Review Article

\title{
Meta-Analysis of the Relationship between Deep Brain Stimulation in Patients with Parkinson's Disease and Performance in Evaluation Tests for Executive Brain Functions
}

\author{
A. M. Martínez-Martínez, ${ }^{1}$ O. M. Aguilar, ${ }^{2}$ and C. A. Acevedo-Triana ${ }^{1}$ \\ ${ }^{1}$ Department of Psychology, Pontificia Universidad Javeriana, Bogotá, Colombia \\ ${ }^{2}$ Department of Brain Repair and Rehabilitation, University College London, London, UK
}

Correspondence should be addressed to C. A. Acevedo-Triana; cesar.acevedo@javeriana.edu.co

Received 25 August 2016; Accepted 11 October 2016; Published 8 February 2017

Academic Editor: Rajka M. Liscic

Copyright (c) 2017 A. M. Martínez-Martínez et al. This is an open access article distributed under the Creative Commons Attribution License, which permits unrestricted use, distribution, and reproduction in any medium, provided the original work is properly cited.

\begin{abstract}
Parkinson's disease (PD) is a neurodegenerative condition, which compromises the motor functions and causes the alteration of some executive brain functions. The presence of changes in cognitive symptoms in PD could be due to the procedure of deep brain stimulation (DBS). We searched in several databases for studies that compared performance in executive function tests before and after the DBS procedure in PE and then performed a meta-analysis. After the initial search, there were 15 articles that specifically evaluated the functions of verbal fluency, working memory, cognitive flexibility, abstract thinking, and inhibition. It was found that there were differences in the evaluation of the cognitive functions in terms of the protocols, which generated heterogeneity in the results of the meta-analysis. Likewise, a tendency to diminish functions like verbal fluency and inhibition was found, being this consistent with similar studies. In the other functions evaluated, no difference was found between pre- and postsurgery scores. Monitoring of this type of function is recommended after the procedure.
\end{abstract}

\section{Introduction}

Parkinson's disease (PD) is a common, progressive and incurable neurodegenerative disease with an unknown etiology, whose main symptoms include motor alterations such as shaking, an abnormal increase in muscle tone, bradykinesia, postural instability, impaired balance and walking, and emotional inexpressiveness [1-6]. In postmortem studies of patients with PD, these clinical features have been directly related to the reduction of dopamine neurons in the corticalthalamus-striated loop [1,4-7], mitochondrial alterations [4], and the presence of clusters of $\alpha$-synuclein presynaptic protein, known as Lewy bodies $[4,7,8]$.

From a neurological perspective, the symptoms of PD have been considered to be the result of alterations in the communication between the direct/indirect motor control pathways of the basal ganglia. According to this "classic" model, this deficiency in communication is given by a reduction in the dopaminergic transmission which in turn results in the diminished inhibition of the indirect pathway, the excitation of the direct pathway, and the excessive activation in the discharge of internal globus pallidus (GPi) and an inhibition of the thalamic cortical motor system $[9,10]$. Given the model's limitations in explaining PD systems other than the motor ones, it is recognized that the Cortico-Basal Ganglia-Thalamus loop is implied in eye movement control functions (the oculomotor circuit) [11], memory and spatial orientation (dorsolateral prefrontal circuit) [10], behavioral adjustment and control, and the reward and punishment system (lateral orbitofrontal circuit) [9].

It has been suggested that cognitive [9], emotional [12], and behavioral [13] alterations can be generated in the BG-cortex communication. In this same sense, although it has not been a characteristic present in all the reports, a significant metabolic reduction has been found in patients with Parkinson's disease, predominantly in areas of parietal and medial frontal association [5].

Among the nonmotor clinical symptoms there is a broad spectrum of alterations at cognitive $[1,9,14]$, emotional, mood [15], behavioral [16, 17], and psychiatric levels [17, 
18]. In some cases, the cognitive deficit is comparable to executive alterations similar to patients with lesions in the frontal lobe, given the reduction of dopaminergic activity in the frontostriatal circuits, but without being considered a "frontal lobe syndrome," leading to episodic alterations and visuospatial and verbal fluency dysfunctions $[9,19]$. Previous studies have reported on the appearance of alterations in tasks that assess executive brain functions, such as verbal fluency [20], Trail Making Test (TMT-B), Wisconsin Card Sorting Test (WCST), Stroop [19], Theory of Mind [21, 22], and timing deficits [23].

The treatments reported for PD include dopamine antagonist pharmacological treatments $[2,3,24]$, physical therapy $[25,26]$, genetic therapy [24], transcranial magnetic stimulation $[15,27,28]$, injury to the subthalamic nucleus [29], and high frequency deep brain stimulation (DBS) [3037]. The latter has been proven to reduce the severity of motor symptoms, to reduce pharmacological treatment significantly, and to improve patients' quality of life $[1,31,32,35$, $36,38-40]$. DBS has been reported in subcortical structures such as the subthalamic nucleus (STN), the internal globus pallidus (GPi), the pedunculopontine nucleus (PPN), and prelemniscal radiation [35, 36, 41-45]. Stimulator frequency depends on the patient's clinical aspects and the location of the electrodes [31, 42].

In the assessment of nonmotor symptoms (disturbed sleep patterns, salivation, mood, cognitive, and executive function), it has been reported that the DBS procedure fosters a number of changes. In DBS of the STN, Bickel et al. [29] found that general performance remained constant in frontal executive function tests $[16,23]$. In bilateral DBS of the STN, significant improvement has been reported in the learning of verbal information and visuoconstructive skills when there is increased stimulator amplitude $[38,46]$. Inasmuch as the DBS of the PPN, improvements have been reported in terms of tasks related to working memory (MT) [23, 47]. It has also been reported that STN-DBS is involved in the generation of impulse control disorders but that this is not a maintained effect [48].

Some studies have identified metabolic changes associated with execution of tasks, reporting that there is an activity reduction network in $\mathrm{PD}$ that includes the supplementary motor area (preSMA), precuneus, the inferior parietal lobe, and the left prefrontal cortex, as well as an increase in the cerebellar vermis and the dentate nucleus, probably due to the cerebellum-BG connections $[5,49]$. Changes in the structures of this area can be seen in tasks that involve cognitive performance which may suggest that alterations in the network play a role in other cognitive functions [50].

A central aspect of this study is the DBS procedure and its impact on nonmotor symptoms in PD [40]. Thus, a metaanalysis of 28 studies was carried out of studies by Parsons et al. [51]. The authors analyzed the cognitive consequences of STN-DBS, concluding that the procedure presents a small effect on all the cognitive domains assessed, except on verbal fluency, shedding light on a lower statistically significant performance in phonetic and semantic verbal fluency tests after DBS.
Given the lack of consensus inasmuch as the impact of the DBS procedure on executive brain functions specifically, the aim of this study was to identify changes in the executive brain functions tests after DBS in six months or more, reported in the last ten years. To do this, we used studies that showed results for before and after DBS and analyzed these using meta-analysis.

\section{Method}

2.1. Study Selection. An information search was carried out in the Scopus databases using the following key words: "deep AND brain AND stimulation AND Parkinson AND executive AND functions." The search yielded 126 articles that covered the 2005-2015 period. Using the same key words, the Pubmed database yielded 39 results; the Web of Science (WOS) database, 104 results; the Sage journals database, 142 results; the Taylor Francis Online database, 125 results; the Wiley Online Library, 1362 results; the Embase database, 149 results; and Proquest, 3295 results. Finally, using the PsychNET database, the search initially gave no results; thus it was modified using the words "Parkinson AND DBS," yielding 6 results. This gave a total of 5348 records in 9 databases. The results were subsequently grouped by year and types of journal articles.

The cleaning process was undertaken in two phases. The first was a selection of articles published in science journals, excluding reviews, meta-analyses, and case studies. The results for this first phase are shown in Figure 1.

2.2. Study Inclusion Criteria. The studies were selected considering the following recommendations: (a) types of design; (b) types of intervention; (c) participant characteristics; (d) statistical data; and (e) the tests used [52]. All the reported studies were written in English and dated between 2005 and 2015. The inclusion criteria for this meta-analysis were the following: (a) pre- and postsurgery testing of stimulator implantation; (b) for the target, the subthalamic nucleus, globus pallidus, and other structures related to movement; (c) sociodemographic variables were not taken into account for participant characteristics (age, how long the patient has had the disease, educational level, and type of medication); (d) studies that reported means, standard deviations, $t$-tests, significance levels; and (e) only those studies that reported some kind of test that assessed executive brain functions (working memory, verbal fluency, cognitive flexibility, planning, inhibition, and abstract thinking) and processing speed. Figure 1 outlines the search procedure. Nonadditional studies were identified by contacting clinical experts and searching bibliographies in local repositories.

2.3. Codification of the Studies. The studies were codified independently by 4 researchers and the codified information was subsequently corroborated. The following characteristics were taken into account for the codification: (a) identification of the study by the first author's surname and the year of publication; (b) the number of participants; (c) the study design (before and after surgery; only after surgery; cases and controls; and correlational); (d) location of implanted 


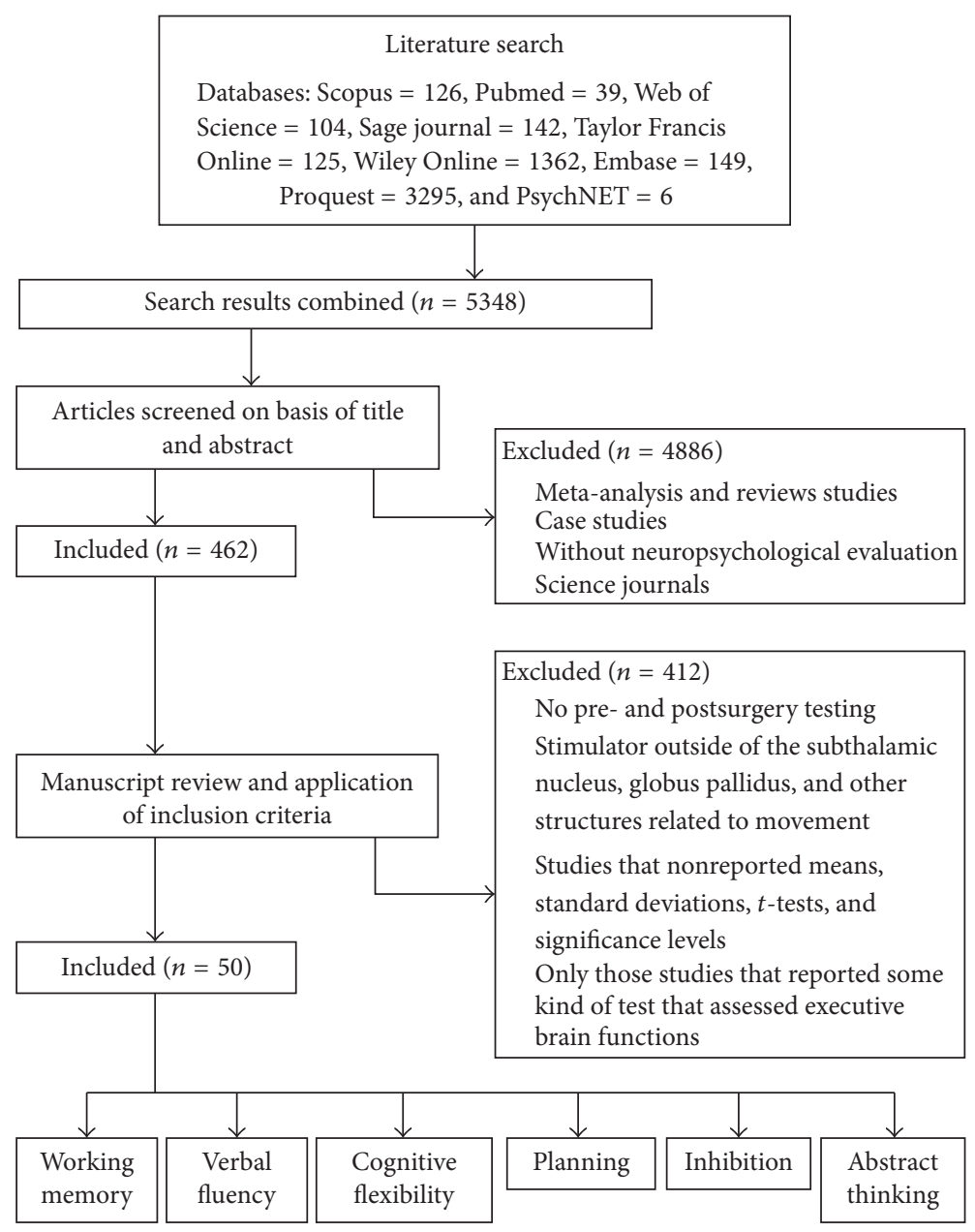

FIgURE 1: Flow diagram of study selection. Adapted from Liberati et al. [53].

deep brain stimulation (subthalamus; globus pallidus; and other); (e) parameter related to the stimulator (pulse, frequency, voltage, and electrode type); (f) schooling (secondary education, university education, graduate studies, none, and not reported); (g) age (under 50, 51-60, 61-70, over 70, and not reported); (h) time of suffering from PD symptoms before brain stimulation surgery (short, less than 5 years; medium, 6-10 years; late, more than 10 years; and not reported); (i) sex (men, women, mixed, and not reported); (j) socioeconomic status (reported, not reported); (k) type of medication; (l) results values associated with the executive brain functions tests undertaken (Table 1); and (m) time before assessment after the stimulator implantation surgery. When the information was codified for the meta-analysis, the time after stimulator implantation variable was not taken as a homogenization criterion for the studies. That is, for those that presented more than one posterior measurement, the measurement closest to 12 months after the surgery was used.

The executive brain functions considered in the study analysis include verbal fluency, cognitive flexibility, working memory, processing speed, behavioral inhibition, and planning (Table 2). Following Parsons et al. [51], the verbal fluency assessment tasks were separated due to the reported systematic reduction of the verbal fluency function in patients with PD with DBS and the difference (category or letters) in terms of task processing.

2.4. Statistical Analysis. The mean scores of the tests undertaken were calculated and Hedges's $g$ values and standard error (SE) for each study are reported together with $95 \%$ confidence intervals (CIs). It was assumed that if value $I^{2}$ was below $50 \%$ of heterogeneity, a meta-analysis with a fixed effects model would be applied; otherwise, a random effects model would be used [57].

To assess the publication bias, a funnel plot was used for each of the meta-analyses [58]. The meta-analysis and funnel plot were carried out using the Comprehensive Meta-analysis 2.0 software. $p<0.05$ value was considered to have statistical significance.

\section{Results}

Once the search was refined, 5348 studies were analyzed (Figure 1). Figure 1 shows the results of the initial search.

3.1. Descriptive. The descriptive results are shown in Table 2 which outlines the studies, number of patients, age, time 


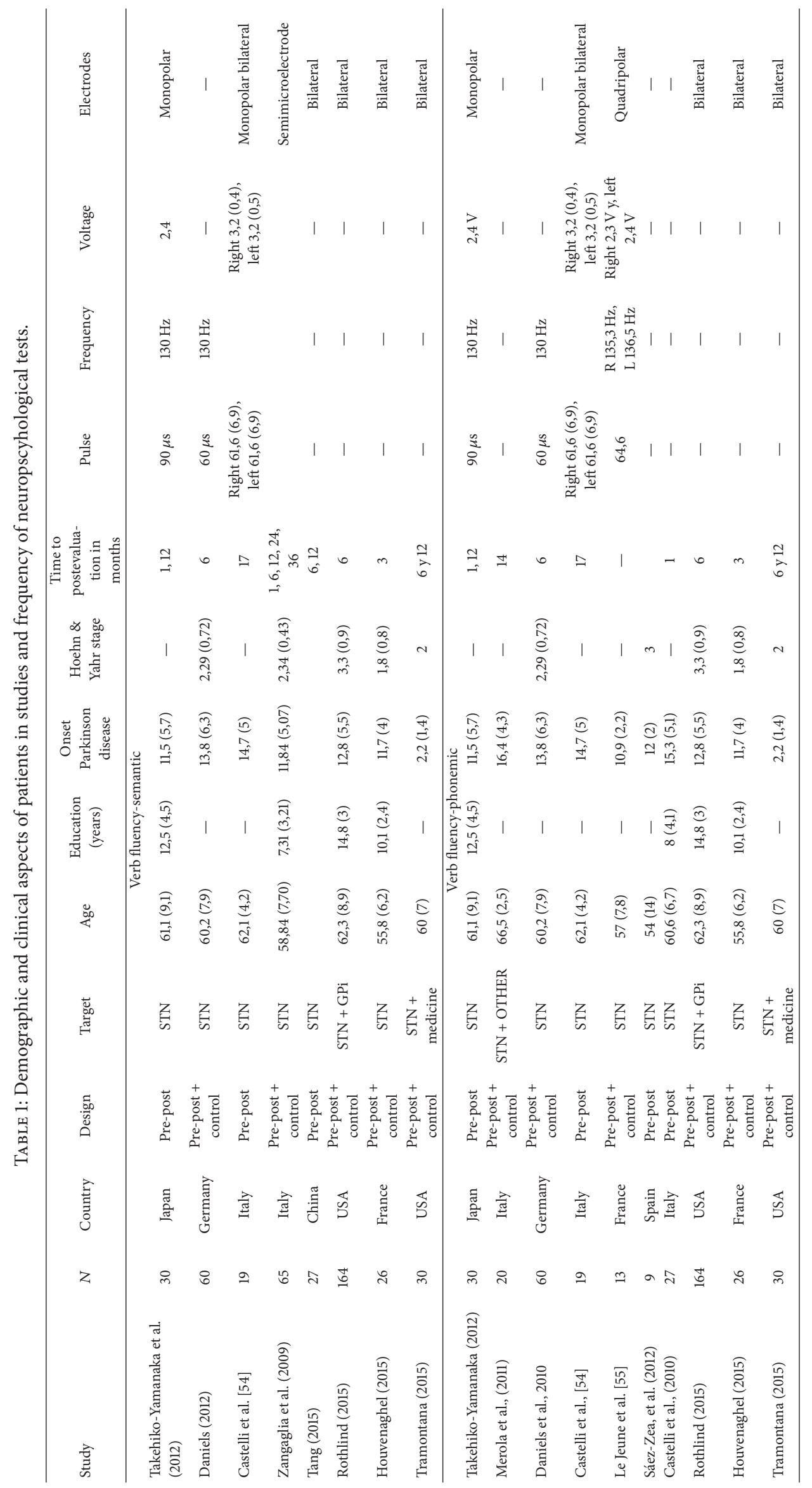




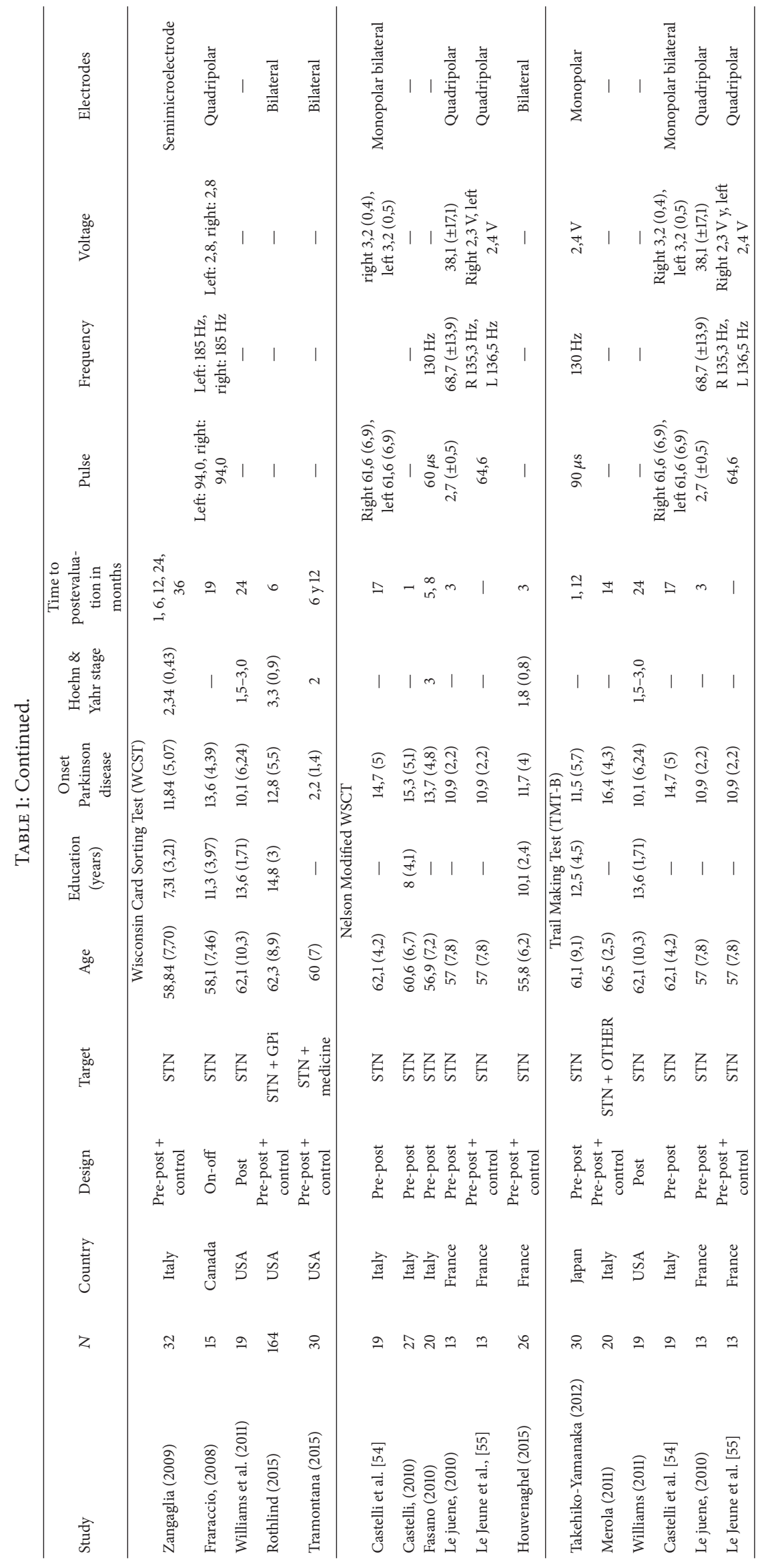




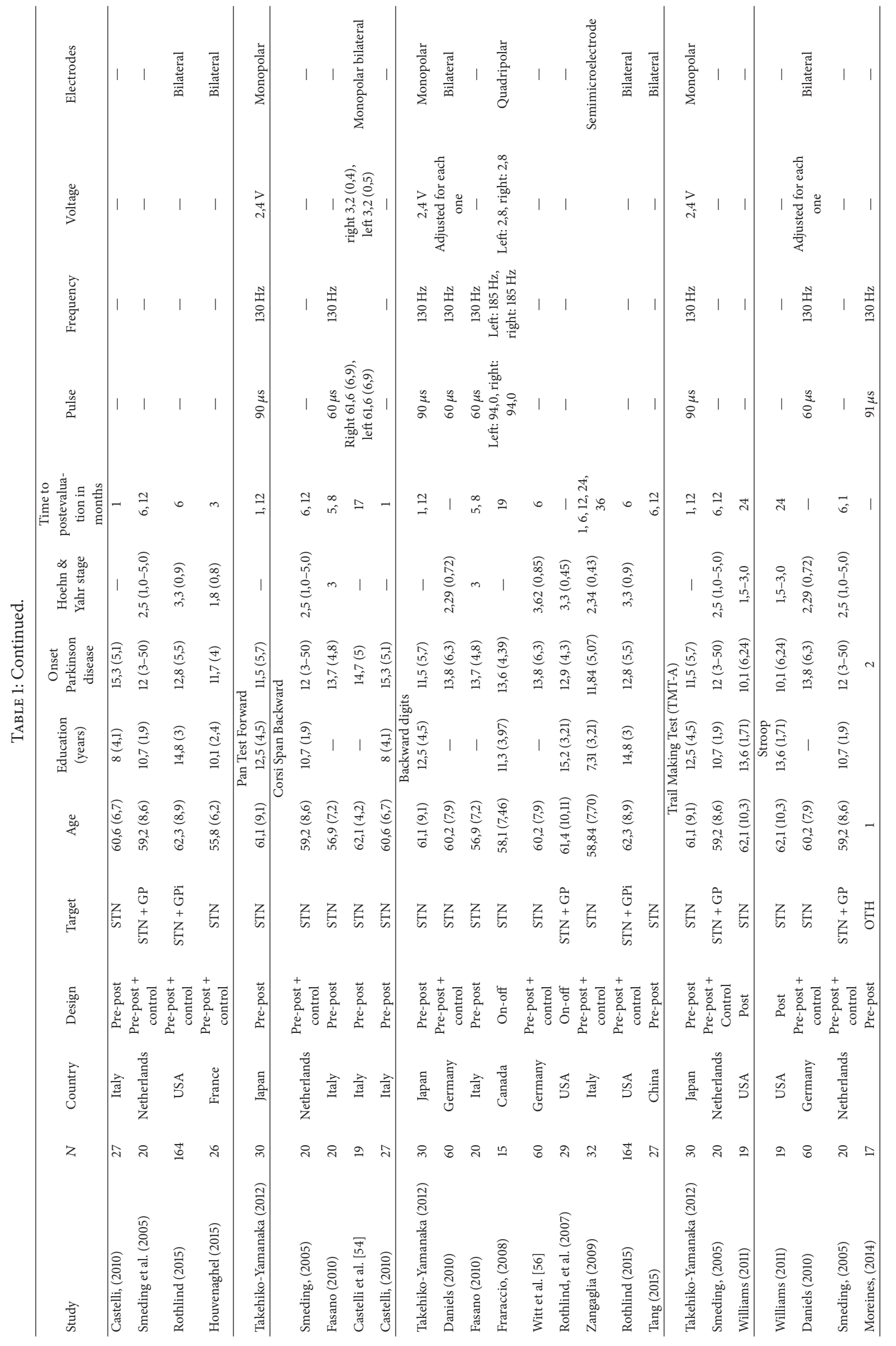




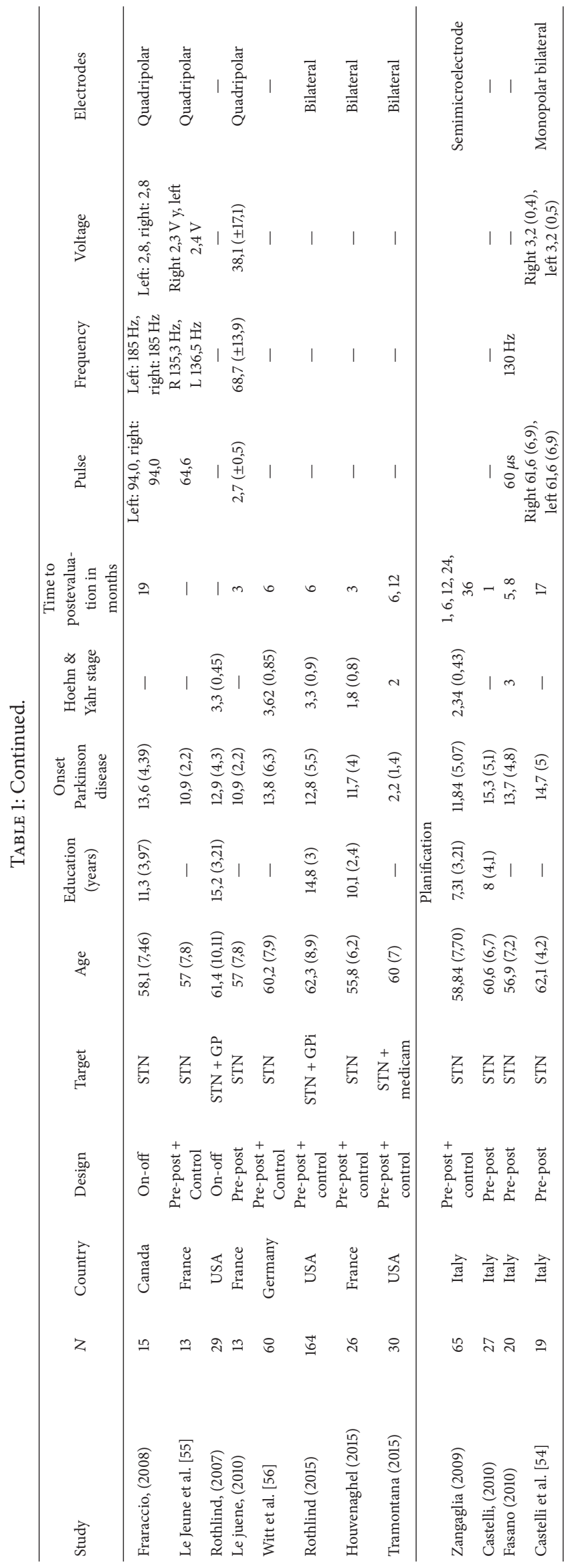


TABLE 2

\begin{tabular}{|c|c|c|c|c|c|c|c|c|}
\hline \multirow{2}{*}{ Neuropsychological test } & \multirow{2}{*}{$k$} & \multirow{2}{*}{$N$} & \multirow{2}{*}{ Age } & \multirow{2}{*}{ Years PD } & \multirow{2}{*}{ DBS } & \multicolumn{3}{|c|}{ Heterogeneity } \\
\hline & & & & & & $Q$ & $p(Q)$ & $I^{2}$ \\
\hline Verbal fluency-semantic & 4 & 141 & 60,56 & 12,96 & STN & & & \\
\hline Verbal fluency-Phonetic & 7 & 178 & 60,21 & 13,51 & STN & 19,769 & 0,032 & 49,41 \\
\hline WSCT & 2 & 51 & 60,47 & 10,97 & STN & & & \\
\hline WSCT-Nelson & 5 & 92 & 58,72 & 13,1 & STN & 34,759 & 0,021 & 42,46 \\
\hline Trail Making Test-B & 8 & 161 & 60,91 & 12,45 & STN & 5,26 & 0,511 & 0,000 \\
\hline Corsi Span Backward & 4 & 86 & 59,86 & 14,56 & STN & & & \\
\hline Digit Span Test & 7 & 246 & 59,22 & 13.06 & STN-GPi & 3,088 & 0,686 & 0,000 \\
\hline Trail Making Test-A & 3 & 69 & 61,6 & 10,8 & STN & 0,581 & 0,748 & 0,000 \\
\hline Stroop & 9 & 246 & 65,2 & 12,18 & STN-Cingulate (1)-GPi (1) & 102,7 & 0,001 & 77,6 \\
\hline Planning & 4 & 98 & 59,61 & 13.85 & STN & & & \\
\hline
\end{tabular}

Note: $k$, number of studies; $N$, number of patients, DBS (deep brain stimulation); Q, heterogeneity intradomain; $p(Q) p$ value of $Q$ statistic; $I^{2}$, percent of heterogeneity from difference.

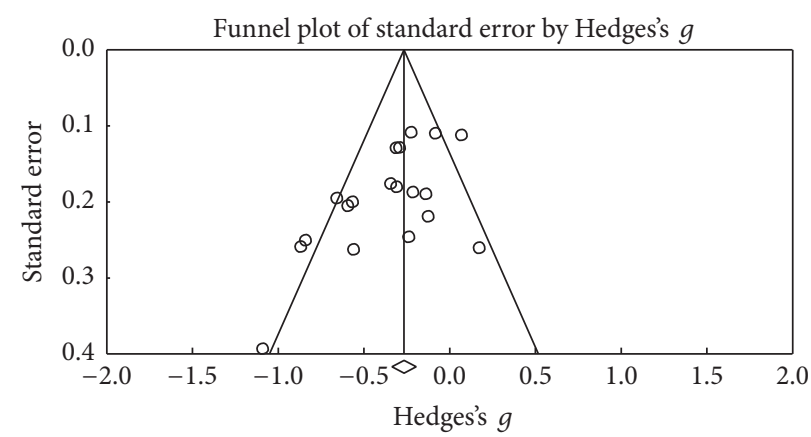

FIGURE 2: Funnel plot for standard error in publications of verbal fluency.

of illness, schooling, PD alteration scores, and other values reported for the studies.

3.2. Meta-Analysis. For this study, a fixed effects model was used due to two conditions. First, the conditions of the participants and characteristics of the disease are similar among the studies and with this a population effect size is theoretically assumed [52, 59]. On the other hand, given that it was previously assumed that the percentage of heterogeneity exceeded $50 \%$ measured by coefficient $I^{2}$, a random effects model was used [57]. It is important to signal that only one study has results of GPi stimulation (Rothlind, 2015) and because of this the results and figures were not separate.

3.3. Verbal Fluency. Figure 2 outlines the funnel plot of the SE for studies of verbal fluency and there is no bias in the studies reported [58]. In this category, we obtained 21 studies that were clustered depending on the evaluation modality (semantic or phonetic), Hedges's $g$ was used to determine the size of the effect, obtaining a medium effect size (Hedges's $g$ $=-0.266 ; \mathrm{SE}=0.036 ; \mathrm{CI}-0.337$ to -0.195$)$, which showed heterogeneity $\left(Q_{(20)}=42,911 ; p=0.002\right)$ within an average percentage $\left(I^{2}=53,39 \%\right)$, which, when in excess of $50 \%$, led to the application of a random model [60]. The results also showed a significant reduction in performance in the test after the DBS procedure $(Z$ value $=-5,607 ; p<0.001)$ (Figure 3$)$.
3.4. Cognitive Flexibility. This function was assessed based on the Wisconsin Shorting Card Test (WSCT) and Trail Making Test (TMT) in its B and B-A versions. Figure 4 shows the funnel plot used for the SE in WSCT; the figure shows three points outside the projection in the upper threshold, but these are shown as equivalents to the points on the lower threshold. The meta-analysis obtained 27 results in which the Wisconsin Shorting Card Test (WSCT) in its different versions (Nelson or Modified) was assessed, bearing in mind the different types of scores (errors, perseverations, or categories). A small effect size was found (Hedges's $g=0.064$; SE $=0.053$; CI -0.04 to 0.167$)$, showing heterogeneity $\left(Q_{(26)}=44,94 ; p=0.012\right)$ within an average percentage $\left(I^{2}=42,14 \%\right)$, but without exceeding $50 \%[43,60]$. There seems to be no significant change in the test scores after the DBS procedure ( $Z$ value $=1,656 ; p=0.098$ ) (Figure 5).

Using the Trail Making Test (TMT-A), 6 results were obtained; Figure 6 shows the funnel plot for the SE of the test, and no biases are observed. The studies in the metaanalysis reveal no differences in terms of execution ( $Z$ value $=-0.328 ; p=0.743$ ), the effect detected was small (Hedges's $g=-0.02 ; \mathrm{SE}=0.061 ; \mathrm{CI}-0.14$ to 0.1$)$, and the results showed homogeneity $\left(Q_{(5)}=3,202 ; p=0.669\right)$ within the $0 \%$ value $\left(I^{2}\right.$ $=0 \%$ ) (Figure 7 ). With respect to the other tests for the same function such as version B of the TMT, 10 of the results found did not reveal an important change between the applications $(Z$ value $=0.912 ; p=0.362)$, the effect detected was small 


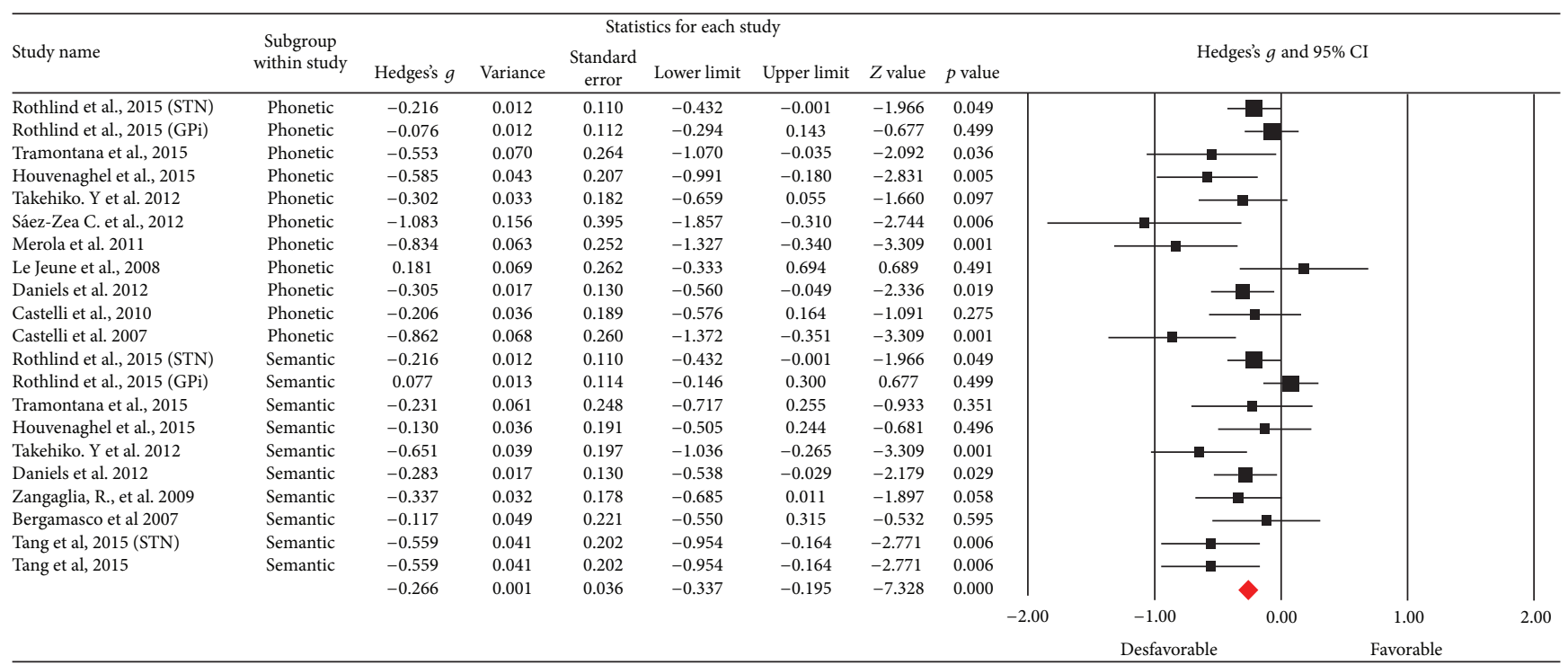

FIGURE 3: Meta-analysis of verbal fluency comparing before and after DBS surgery. Verbal fluency was separated in phonetic and semantic parts. STN = subthalamic nucleus; GPi = internal globus pallidus.

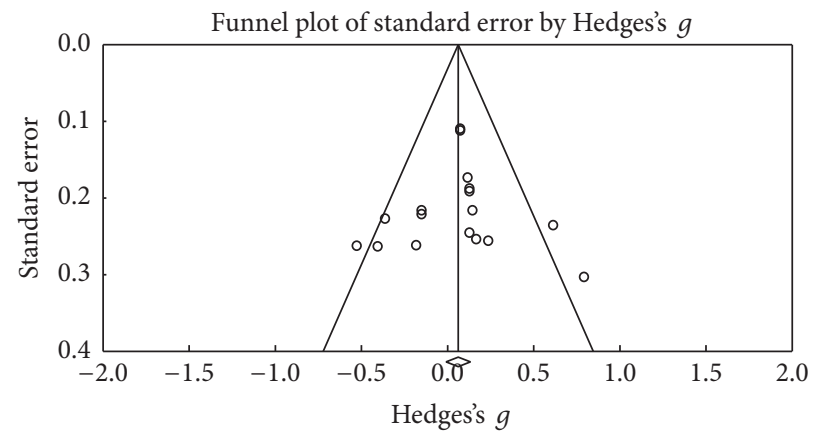

FIGURE 4: Funnel plot for standard error in publications of cognitive flexibility (WSCT).

(Hedges's $g=-0.02 ; \mathrm{SE}=0.053 ; \mathrm{CI}-0.056$ to 0.153 ), and the results showed homogeneity $\left(Q_{(9)}=6,973 ; p=0.64\right)$ at a very low percentage $\left(I^{2}=0 \%\right)$ (Figure 9$)$. Figure 8 presents the funnel plot for the SE of the TMT-B. Finally, for the TMT-B-A version (5 results) the funnel plot is presented in Figure 10 and no differences were found between applications before and after the DBS procedure $(Z$ value $=-0.404 ; p=0.686)$. The effect detected was small (Hedges's $g=-0.04$; $\mathrm{SE}=0.099$; CI -0.234 to 0.154$)$, and the results showed homogeneity $\left(Q_{(4)}=\right.$ $2,251 ; p=0.69)$ at a very low percentage $\left(I^{2}=0 \%\right)$ (Figure 11$)$.

3.5. Abstract Thinking. Figure 12 shows the funnel plot and no bias among the studies was observed. In this category, 6 studies were obtained, and no changes in test performance were observed after the DBS procedure $(Z$ value $=0.722$; $p=0.471$ ) (Figure 13). A small effect size was obtained (Hedges's $g=0.058$; $\mathrm{SE}=0.080$; CI -0.099 to 0.215 ), and the result showed homogeneity $\left(Q_{(5)}=3,088 ; p=0.686\right)$ within a low percentage $\left(I^{2}=0 \%\right)$.

3.6. Working Memory. Figure 14 shows the funnel plot and no bias among the studies is observed. In this category, 22 results were obtained, and no changes in test performance were observed after the DBS procedure $(Z$ value $=-1,533$; $p=0.125$ ) (Figure 15). A small effect size was obtained (Hedges's $g=-0.051$; $\mathrm{SE}=0.033$; CI -0.115 to 0.014 ), and the result showed homogeneity $\left(Q_{(21)}=13,682 ; p=0.883\right)$ at a low percentage $\left(I^{2}=0 \%\right)$.

3.7. Inhibition. Figure 16 shows the funnel plot for inhibition; a number of scores outside the lower and upper thresholds were obtained suggesting a bias in the studies. However, when visual criteria were applied, the bias does not present itself fully, and there are a number of points close to the upper threshold. What does result from this analysis is a high degree of heterogeneity between the studies $\left(Q_{(40)}=88,95\right.$; $p<0.001)$ corresponding to over $89 \%$ of the variability among them $\left(I^{2}=55,03 \%\right)$. In this category, 41 results were obtained.

Given this heterogeneity, a random model meta-analysis was applied and a change in the execution of the test was observed as it significantly reduced after the DBS procedure $(Z$ value $=-0.406 ; p<0.001)$ (Figure 17). A small effect size was found (Hedges's $g=-0.211$; $\mathrm{SE}=0.039$; CI -0.268 to -0.135$)$. 


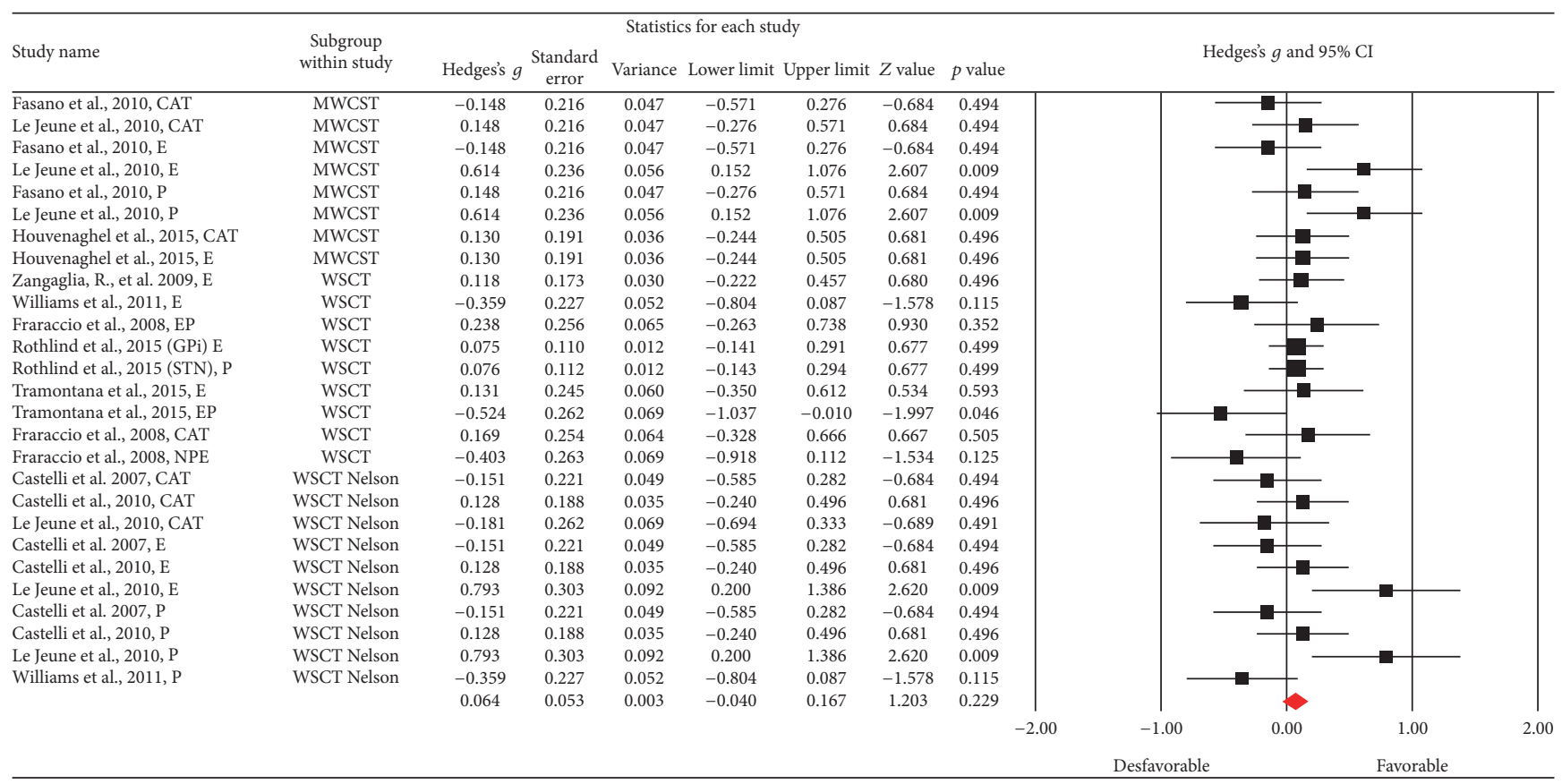

FIGURE 5: Meta-analysis of WSCT comparing before and after DBS surgery. The Wisconsin Short Card Test had three versions. Version one: MWCST = modified WCST; version two: WSCT; and version three: WSCT Nelson version.

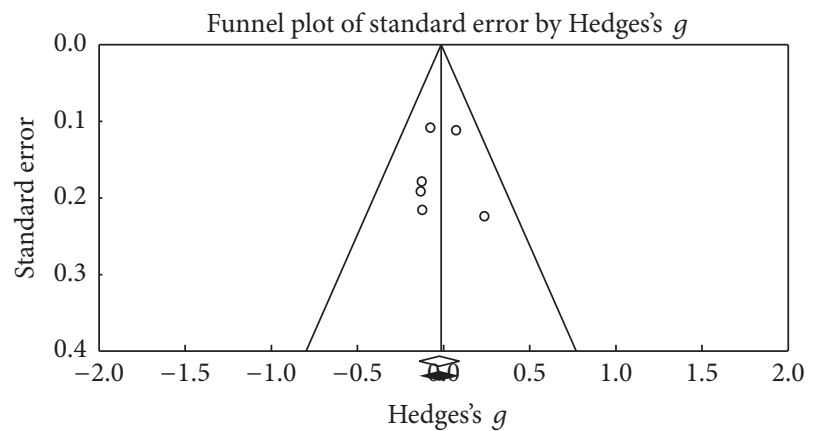

FIGURE 6: Funnel plot for standard error in publications of Trail Making Test (TMT-A).

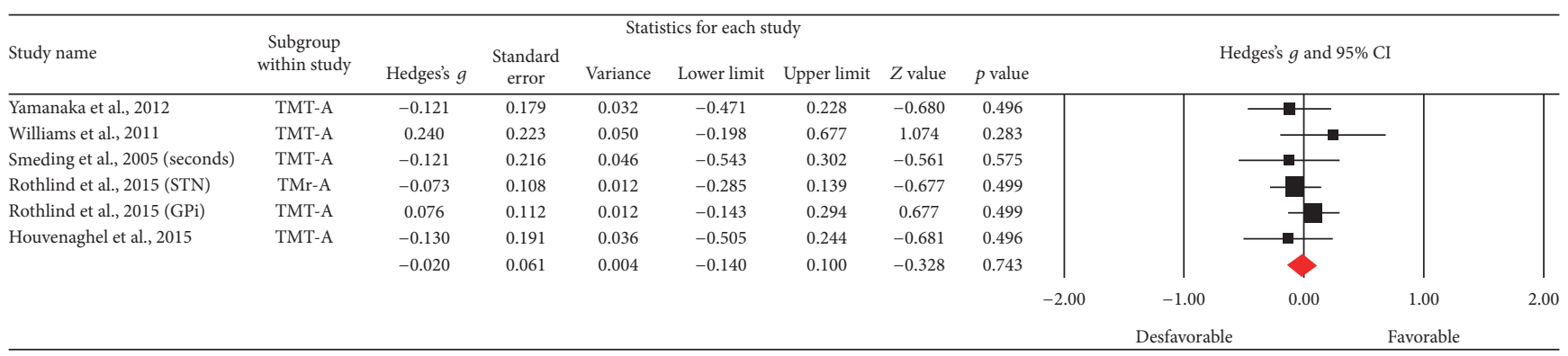

FIgURE 7: Meta-analysis of TMT-A comparing before and after DBS surgery.

\section{Discussion}

The results of this study were found to correspond to similar studies in which there is a general reduction of executive brain functions after the DBS procedure. This does not seem to have an impact on quality of life given the improvement of motor symptoms $[19,51,61]$. It is worth highlighting that the study of EF has shown a reduction in tasks such as WCST, verbal fluency, and Stroop in patients with PD before the DBS procedure. This could be explained by alterations in the BGdorsolateral prefrontal cortex loop in relation to the reduction 


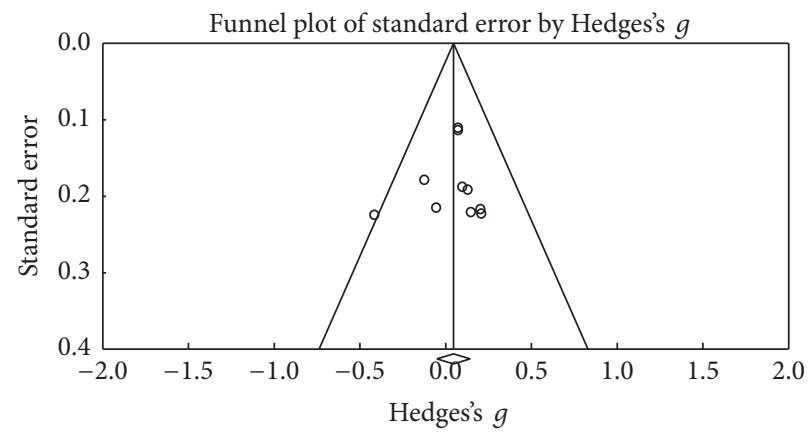

FIGURE 8: Funnel plot for standard error in publications of Trail Making Test (TMT-B).

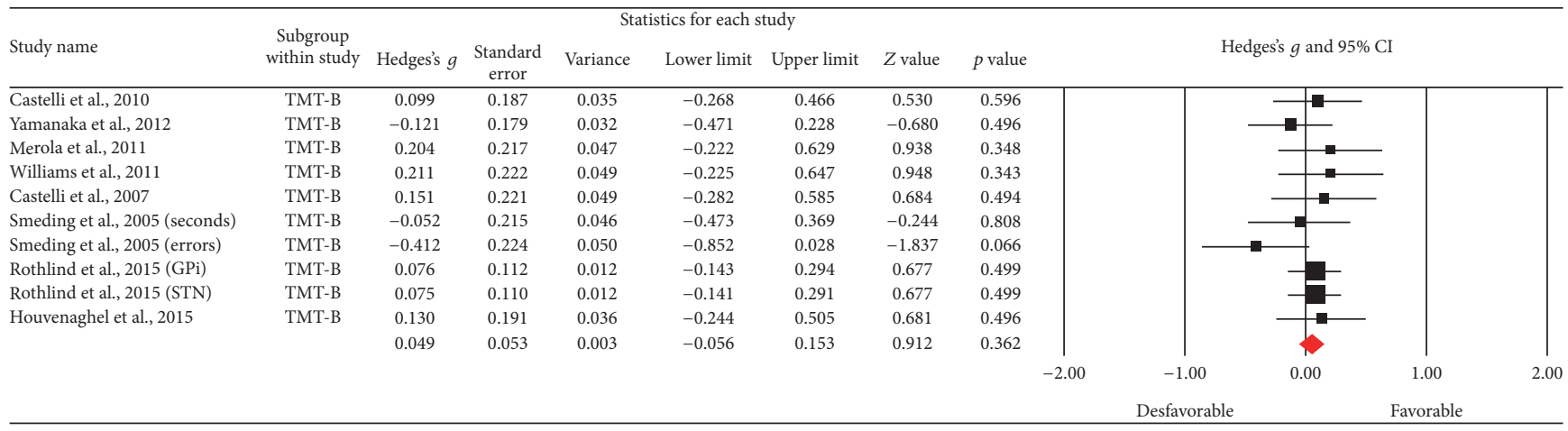

FIGURE 9: Meta-analysis of TMT-B comparing before and after DBS surgery.

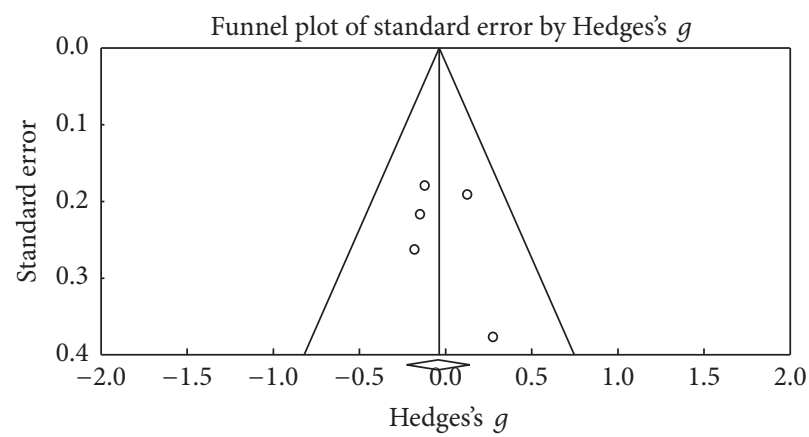

FIGURE 10: Funnel plot for standard error in publications of Trail Making Test (TMT-AB).

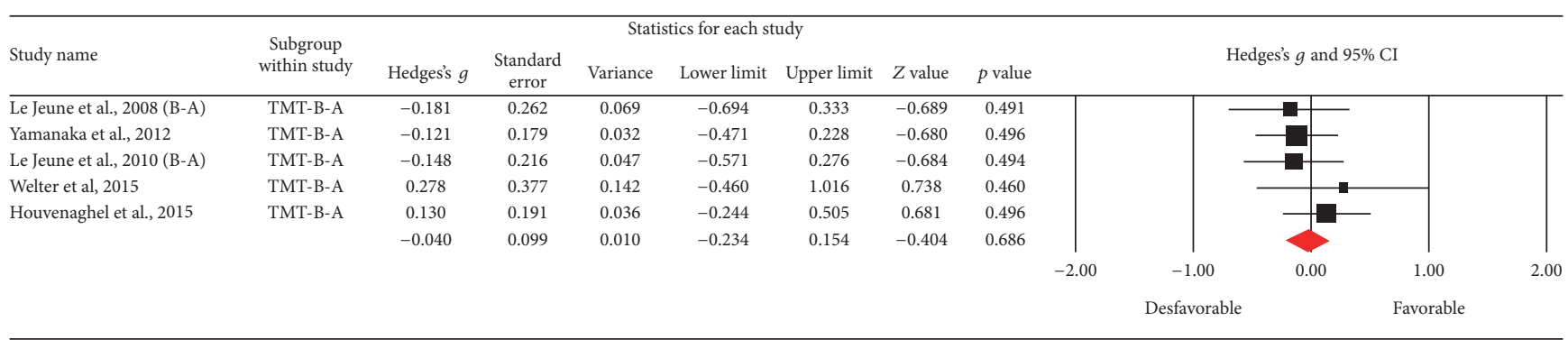




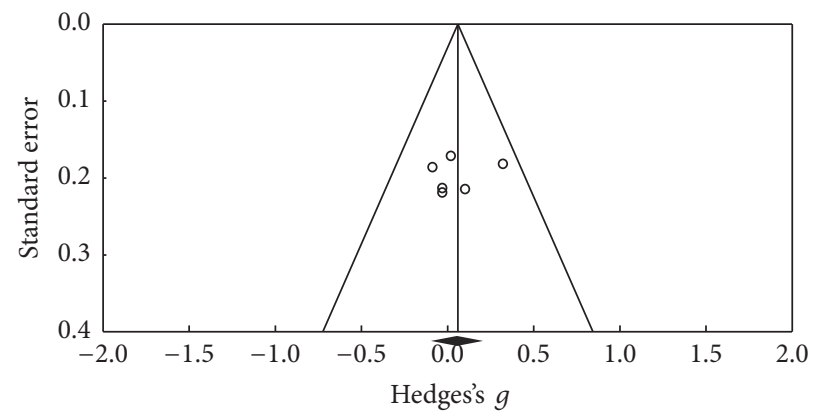

FIGURE 12: Funnel plot for standard error in publications of Raven Matrix.

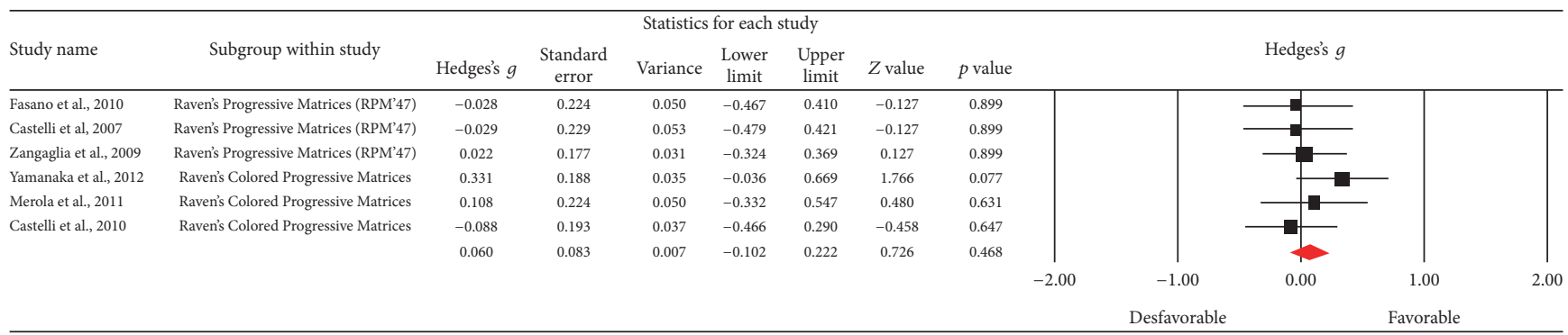

The thinking abstract function was evaluated with Raven Matrix in two versions: Progressive (RPM'47) and Colored.

FIGURE 13: Meta-analysis of Raven Matrix comparing before and after DBS surgery.

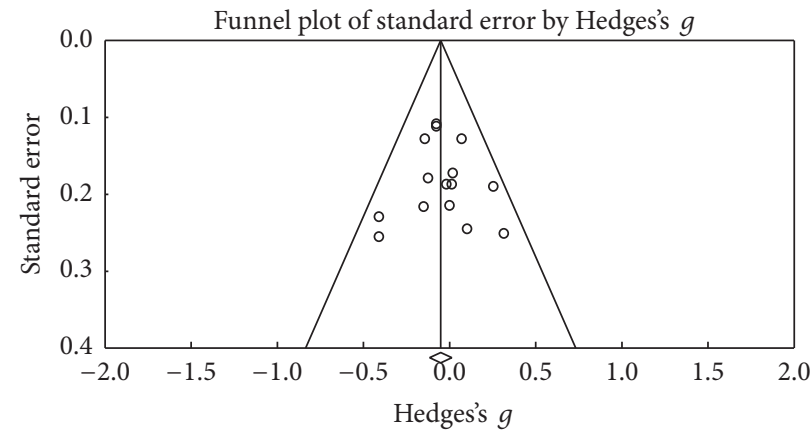

FIGURE 14: Funnel plot for standard error in publications of Digit Span Test (DST).

of dopamine in the nigrostriatal and mesocortical pathways [10].

In general, the study of EF presents a difficulty in terms of the unification of concepts. It has been recognized that the lack of unity in the measurements and significance makes it difficult to establish the relationship with clinical aspects and to explain the improvement or reduction of the functions tested [19]. Following Kudlicka et al. [19], the conclusions are due to the performance in the tests presented without this being an exhaustive analysis of EF. With this, it was found in a number of studies that the same test was used to assess various functions. The lack of representation of Latin American individuals and the lack of studies carried out in Latin America are notable.

The meta-analysis studies and systematic reviews have identified important aspects of PD that could explain part of the emotional functioning, that is, a deficit of emotional recognition which, although not reported in other clinical studies of $\mathrm{PD}$, could help improve communication processes and mood alterations [62]. Such studies can also help us understand the possible relationship between structures such as STN and the structures involved in emotional and cognitive processes [55] and, as such, better understand the disease as a whole.

In the case of the verbal fluency tests, a deterioration has been reported for PD both with pharmacological treatment and with DBS [54]. There is a change in verbal fluency performance with DBS, and this is coherent with other studies and meta-analyses in which a reduction in performance is reported $[46,51,56]$. This alteration has been related to the position of the electrodes on the STN in the left hemisphere [63]. In neuroimaging studies of patients with $\mathrm{PD}$, an associative-type reduction of the metabolic function of the frontal and parietal areas has been found [5], and other 


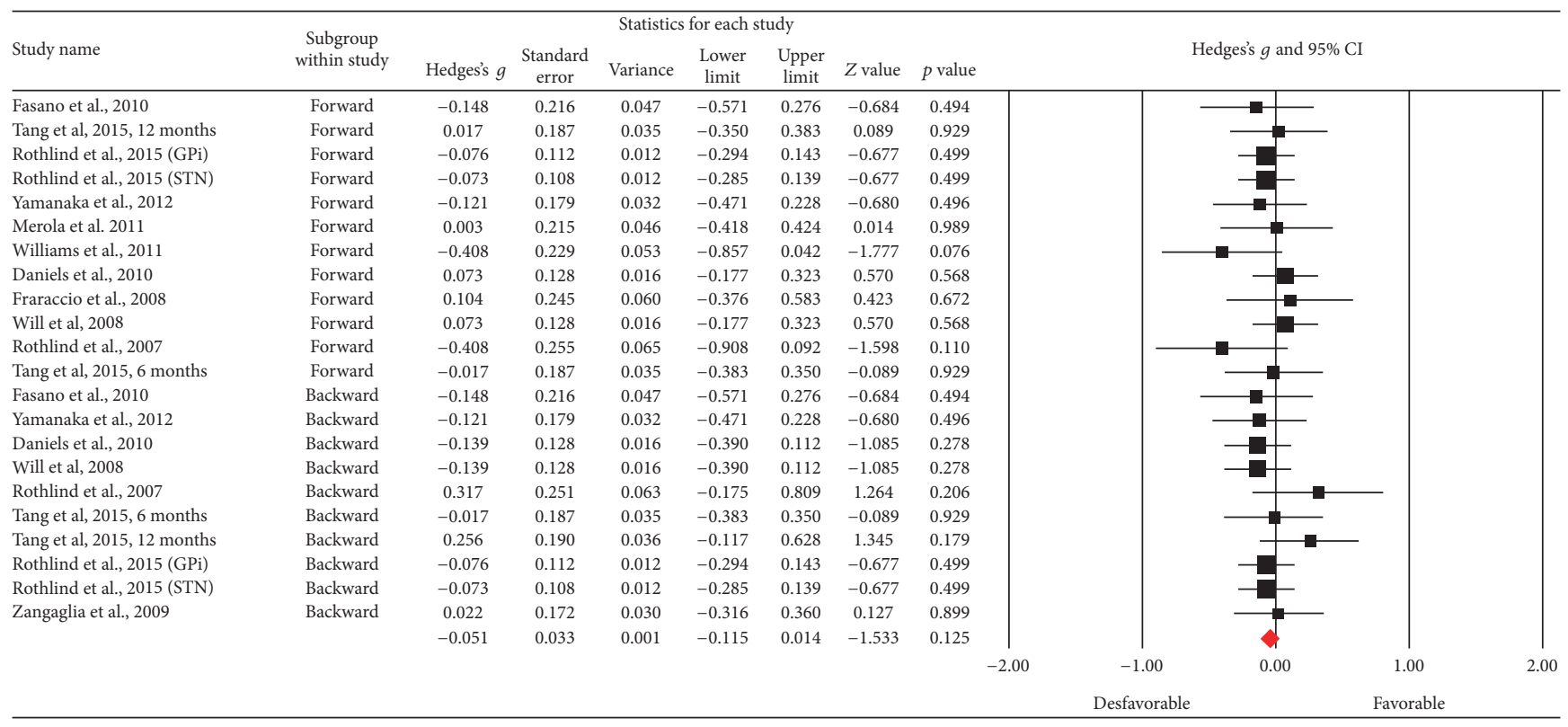

FIGURE 15: Meta-analysis of DST comparing before and after DBS surgery.

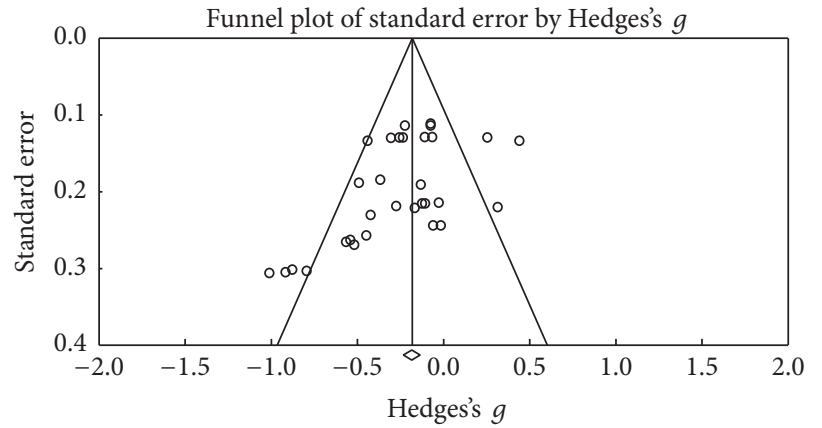

FIGURE 16: Funnel plot for standard error in publications of Stroop Test.

studies suggest that the striate nucleus may play a dissociable role in motor control and language cognitive processes, which would mean that different patterns of stimulation would affect the structures of the basal ganglia and cortical regions in different ways. This, in turn, explains why some patients improve in terms of their language articulation and at the same time present a reduction in their verbal fluency after DBS [51]. It has also been reported that the stimulation may cause a decrease of activity in the temporal cortex and inferior frontal areas in the left hemisphere, which would decrease verbal fluency, especially of the phonological kind [64]. Nevertheless, it is necessary to highlight that these hypotheses are still under study.

Inasmuch as heterogeneity, this can be explained based on the variability in the rigorousness of the application and the standardized test to assess it. Given that the reported heterogeneity is close to $45 \%$, it is proposed that the effect detected cannot necessarily be attributed to the DBS procedure.

Inasmuch as cognitive flexibility, the tests assessed do not show a significant change, despite being one of the functions which in other studies is reported as favorable [56]. Similarly, the working memory function has been proposed as one of the aspects that becomes altered in PD. More alterations have been identified in the visuospatial modality than the verbal modality $[47,65]$, and no significant changes are reported in this study for after DBS.

Inasmuch as the Stroop, no clear effect was identified perhaps due to the high heterogeneity of the studies that may be assumed as being derived from the alternative forms of the test [56].

On the other hand, another type of meta-analysis in PD has been carried out, linking the disease to different levels; for example, a genetic level which shows susceptibility to PD depending on polymorphisms in monoamine oxidase genes (MAO) [66], with other diseases or effects of the transcranial magnetic stimulation $[15,27]$. This sheds light on the fact that there is a variety of studies that attempt to explain specific aspects of PD, but, as yet, with no unity of analysis that allows us to understand the diversity of the symptoms of patients with PD.

One of the difficulties reported in establishing a STN-DBS effect in systematic changes in the patients and that explains 


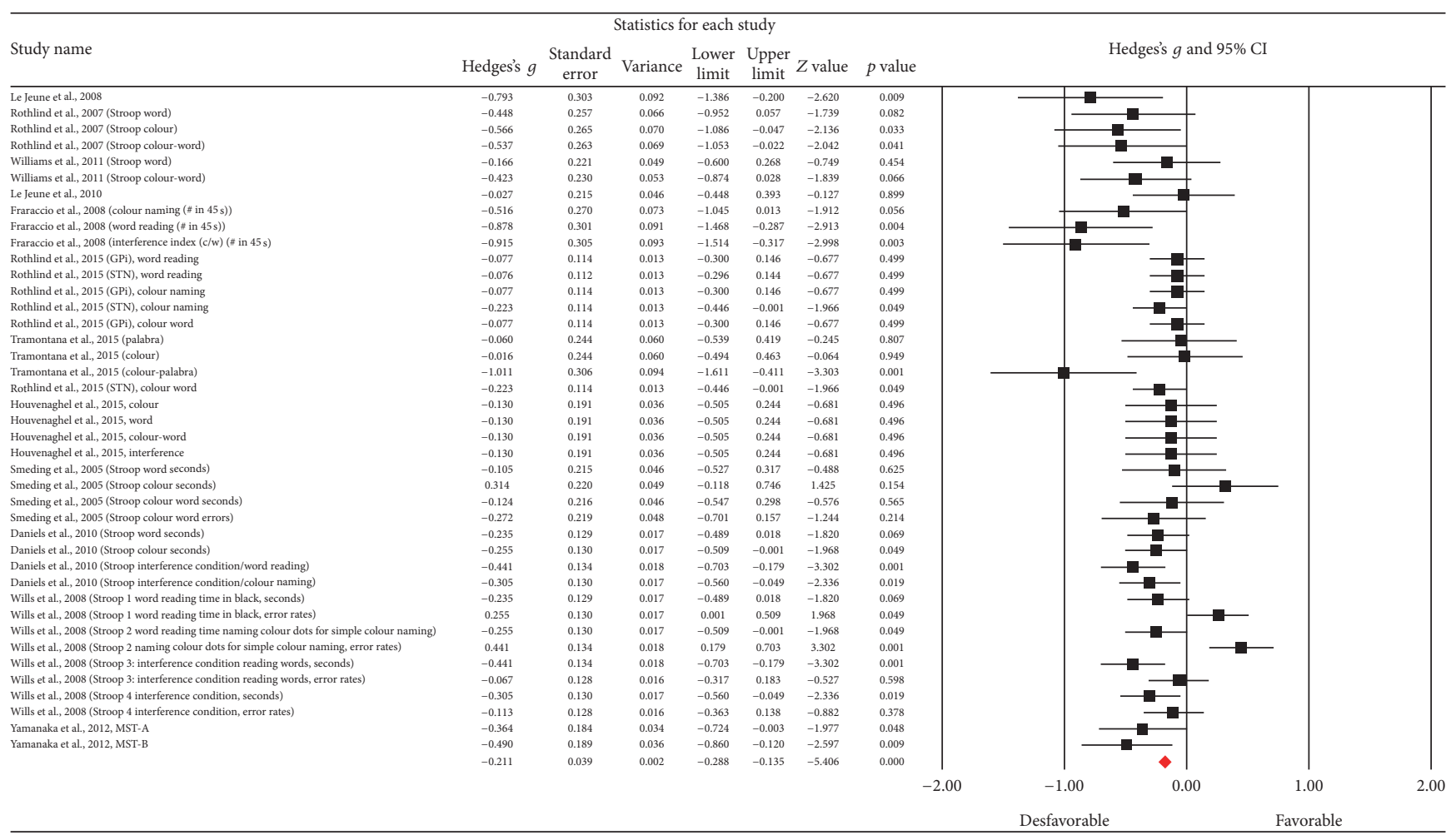

FIgURE 17: Meta-analysis of Stroop Test comparing before and after DBS surgery.

the variability of the effects, as well as the tasks, is the exact location of the electrodes. In this respect, it has been found that although the procedure is carried out in STN, the area of location, the area of active stimulation, or the volume of electrode contact is not always homogeneous $[6,63,67]$.

Another of the major difficulties in the systematic assessment of the changes realized by the DBS procedure is the lack of standardized tests to measure the functions [16]. In this study, high variability was found in the versions of some of the tests which could be a factor that contributes to the heterogeneity. On the other hand, it has also been proposed that the alterations presented in $\mathrm{PD}$ do not always correlate with the specific alterations related to the treatment (e.g., pharmacological). Thus, the alterations in the different domains and the lack of EF improvement after DBS treatment may respond to a nonlinear model that involves different and complex circuits that are not necessarily modified by STNDBS [68].

Finally, one of the important limitations to detecting of the effects of the procedure is the lack of control or placebo groups that would allow the identification of DBS [56].

\section{Competing Interests}

The authors declare that there is no conflict of interests regarding the publication of this paper.

\section{Acknowledgments}

This paper was made possible thanks to funding of Vicerrectoría de Investigación of the Pontificia Universidad Javeriana with ID Project: 00006578, titled "Effects of Deep Brain Stimulation (DBS) on Performance of Executive Function Test in Patients with Parkinson's Disease."

\section{References}

[1] O. M. Aguilar, C. A. Soto, and M. Esguerra, "Cambios neuropsicológicos asociados a estimulación cerebral profunda en enfermedad de Parkinson: revisión teórica," Suma Psicológica, vol. 18, no. 2, pp. 89-98, 2011.

[2] G. J. Demakis, "The neuropsychology of Parkinson's disease," Disease-a-Month: DM, vol. 53, no. 3, pp. 152-155, 2007.

[3] S. Factor and W. Weiner, Parkinson's Disease: Diagnosis \& Clinical Management? Demos Medical, 2nd edition, 2007.

[4] N. A. Haelterman, W. H. Yoon, H. Sandoval, M. Jaiswal, J. M. Shulman, and H. J. Bellen, "A mitocentric view of Parkinson's disease," Annual Review of Neuroscience, vol. 37, pp. 137-159, 2014.

[5] C. Huang, P. Mattis, C. Tang, K. Perrine, M. Carbon, and D. Eidelberg, "Metabolic brain networks associated with cognitive function in Parkinson's disease," NeuroImage, vol. 34, no. 2, pp. 714-723, 2007.

[6] Y. Liu, W. Li, C. Tan et al., "Meta-analysis comparing deep brain stimulation of the globus pallidus and subthalamic nucleus to treat advanced Parkinson disease," Journal of Neurosurgery, vol. 121, no. 3, pp. 709-718, 2014.

[7] A. J. Lees, J. Hardy, and T. Revesz, "Parkinson's disease," The Lancet, vol. 373, no. 9680, pp. 2055-2066, 2009.

[8] K. Wakabayashi, F. Mori, and H. Takahashi, "Progression patterns of neuronal loss and Lewy body pathology in the substantia nigra in Parkinson's disease," Parkinsonism \& Related Disorders, vol. 12, no. 2, pp. S92-S98, 2006. 
[9] A. L. Bartels and K. L. Leenders, "Parkinson's disease: the syndrome, the pathogenesis and pathophysiology," Cortex, vol. 45, no. 8, pp. 915-921, 2009.

[10] M. C. Rodriguez-Oroz, M. Jahanshahi, P. Krack et al., "Initial clinical manifestations of Parkinson's disease: features and pathophysiological mechanisms," The Lancet Neurology, vol. 8, no. 12, pp. 1128-1139, 2009.

[11] J. M. Chambers and T. J. Prescott, "Response times for visually guided saccades in persons with Parkinson's disease: a metaanalytic review," Neuropsychologia, vol. 48, no. 4, pp. 887-899, 2010.

[12] M. E. Bodden, R. Dodel, and E. Kalbe, "Theory of mind in Parkinson's disease and related basal ganglia disorders: a systematic review," Movement Disorders, vol. 25, no. 1, pp. 1327, 2010.

[13] T. A. Mestre, A. P. Strafella, T. Thomsen, V. Voon, and J. Miyasaki, "Diagnosis and treatment of impulse control disorders in patients with movement disorders," Therapeutic Advances in Neurological Disorders, vol. 6, no. 3, pp. 175-188, 2013.

[14] J. V. Hindle, A. Martyr, and L. Clare, "Cognitive reserve in Parkinson's disease: a systematic review and meta-analysis," Parkinsonism \& Related Disorders, vol. 20, no. 1, pp. 1-7, 2014.

[15] C.-L. Xie, J. Chen, X.-D. Wang et al., "Repetitive transcranial magnetic stimulation (rTMS) for the treatment of depression in Parkinson disease: a meta-analysis of randomized controlled clinical trials," Neurological Sciences, vol. 36, no. 10, pp. 17511761, 2015.

[16] M. Denheyer, Z. H. Kiss, and A. M. Haffenden, "Behavioral effects of subthalamic deep brain stimulation in Parkinson's disease," Neuropsychologia, vol. 47, no. 14, pp. 3203-3209, 2009.

[17] V. Voon, K. Hassan, M. Zurowski et al., "Prevalence of repetitive and reward-seeking behaviors in Parkinson disease," Neurology, vol. 67, no. 7, pp. 1254-1257, 2006.

[18] V. Voon, C. Kubu, P. Krack, J.-L. Houeto, and A. I. Tröster, "Deep brain stimulation: neuropsychological and neuropsychiatric issues," Movement Disorders, vol. 21, no. S14, pp. S305-S327, 2006.

[19] A. Kudlicka, L. Clare, and J. V. Hindle, "Executive functions in Parkinson's disease: systematic review and meta-analysis," Movement Disorders, vol. 26, no. 13, pp. 2305-2315, 2011.

[20] D. Zgaljardic, J. Borod, N. Foldi et al., "An examination of executive dysfunction associated with frontostriatal circuitry in Parkinson's disease," Journal of Clinical and Experimental Neuropsychology, vol. 28, no. 7, pp. 1127-1144, 2006.

[21] M. E. Bodden, B. Mollenhauer, C. Trenkwalder et al., "Affective and cognitive theory of mind in patients with Parkinson's disease," Parkinsonism \& Related Disorders, vol. 16, no. 7, pp. 466-470, 2010.

[22] M. Poletti, I. Enrici, and M. Adenzato, "Cognitive and affective Theory of Mind in neurodegenerative diseases: neuropsychological, neuroanatomical and neurochemical levels," Neuroscience and Biobehavioral Reviews, vol. 36, no. 9, pp. 2147-2164, 2012.

[23] K. L. Parker, D. Lamichhane, M. S. Caetano, and N. S. Narayanan, "Executive dysfunction in Parkinson's disease and timing deficits," Frontiers in Integrative Neuroscience, vol. 7, article 75, 2013.

[24] Y. Smith, T. Wichmann, S. A. Factor, and M. R. Delong, "Parkinson's disease therapeutics: new developments and challenges since the introduction of levodopa," Neuropsychopharmacology, vol. 37, no. 1, pp. 213-246, 2012.
[25] T. M. Cruickshank, A. R. Reyes, and M. R. Ziman, “A systematic review and meta-analysis of strength training in individuals with multiple sclerosis or Parkinson disease," Medicine, vol. 94, no. 4, article e411, 2015.

[26] F. M. Weaver, K. Follett, M. Stern et al., "Bilateral deep brain stimulation vs best medical therapy for patients with advanced parkinson disease: a randomized controlled trial," JAMA-Journal of the American Medical Association, vol. 301, no. 1, pp. 63-73, 2009.

[27] Y.-H. Chou, P. T. Hickey, M. Sundman, A. W. Song, and N.-K. Chen, "Effects of repetitive transcranial magnetic stimulation on motor symptoms in parkinson disease: a systematic review and meta-analysis," JAMA Neurology, vol. 72, no. 4, pp. 432440, 2015.

[28] H. Zhu, Z. Lu, Y. Jin, X. Duan, J. Teng, and D. Duan, "Low-frequency repetitive transcranial magnetic stimulation on Parkinson motor function: a meta-analysis of randomised controlled trials," Acta Neuropsychiatrica, vol. 27, no. 2, pp. 8289, 2015.

[29] S. Bickel, L. Alvarez, R. Macias et al., "Cognitive and neuropsychiatric effects of subthalamotomy for Parkinson's disease," Parkinsonism and Related Disorders, vol. 16, no. 8, pp. 535-539, 2010.

[30] F. Agnesi, M. D. Johnson, and J. L. Vitek, "Deep brain stimulation: how does it work?" in Handbook of Clinical Neurology, vol. 116, pp. 39-54, Elsevier, 2013.

[31] A. L. Benabid, S. Chabardes, J. Mitrofanis, and P. Pollak, "Deep brain stimulation of the subthalamic nucleus for the treatment of Parkinson's disease," The Lancet Neurology, vol. 8, no. 1, pp. 67-81, 2009.

[32] G. Giannicola, S. Marceglia, L. Rossi et al., "The effects of levodopa and ongoing deep brain stimulation on subthalamic beta oscillations in Parkinson's disease," Experimental Neurology, vol. 226, no. 1, pp. 120-127, 2010.

[33] M. Jahanshahi, C. R. G. Jones, J. Zijlmans et al., "Dopaminergic modulation of striato-frontal connectivity during motor timing in Parkinson's disease," Brain, vol. 133, part 3, pp. 727-745, 2010.

[34] C. Juri, M. Rodriguez-Oroz, and J. A. Obeso, "The pathophysiological basis of sensory disturbances in Parkinson's disease," Journal of the Neurological Sciences, vol. 289, no. 1-2, pp. 60-65, 2010.

[35] G. Kleiner-Fisman, J. Herzog, D. N. Fisman et al., "Subthalamic nucleus deep brain stimulation: summary and meta-analysis of outcomes," Movement Disorders, vol. 21, supplement 1, pp. S290-304, 2006.

[36] M. K. Lyons, "Deep brain stimulation: current and future clinical applications," Mayo Clinic Proceedings, vol. 86, no. 7, pp. 662-672, 2011.

[37] J. A. Obeso, M. C. Rodríguez-Oroz, M. Rodríguez et al., "Pathophysiology of the basal ganglia in Parkinson's disease," Trends in Neurosciences, vol. 23, no. 10, pp. S8-S19, 2000.

[38] D. Cyron, M. Funk, M.-A. Deletter, and K. Scheufler, "Preserved cognition after deep brain stimulation (DBS) in the subthalamic area for Parkinson's disease: a case report," Acta Neurochirurgica, vol. 152, no. 12, pp. 2097-2100, 2010.

[39] P. Dowsey-Limousin and P. Pollak, "Deep brain stimulation in the treatment of Parkinson's disease: a review and update," Clinical Neuroscience Research, vol. 1, no. 6, pp. 521-526, 2001.

[40] J. M. Nazzaro, R. Pahwa, and K. E. Lyons, "The impact of bilateral subthalamic stimulation on non-motor symptoms of Parkinson's disease," Parkinsonism \& Related Disorders, vol. 17, no. 8, pp. 606-609, 2011. 
[41] M. Deogaonkar, G. A. Monsalve, J. Scott, A. Ahmed, and A. Rezai, "Bilateral subthalamic deep brain stimulation after bilateral pallidal deep brain stimulation for Parkinson's disease," Stereotactic and Functional Neurosurgery, vol. 89, no. 2, pp. 123127, 2011.

[42] A. Franzini, R. Cordella, G. Messina et al., "Deep brain stimulation for movement disorders. Considerations on 276 consecutive patients," Journal of Neural Transmission, vol. 118, no. 10, pp. 1497-1510, 2011.

[43] M. D. Johnson, S. Miocinovic, C. C. McIntyre, and J. L. Vitek, "Mechanisms and targets of deep brain stimulation in movement disorders," Neurotherapeutics, vol. 5, no. 2, pp. 294308, 2008.

[44] P. Limousin and I. Martinez-Torres, "Deep brain stimulation for Parkinson's disease," Neurotherapeutics, vol. 5, no. 2, pp. 309319, 2008.

[45] F. Weaver, K. Follett, K. Hur, D. Ippolito, and M. Stern, “Deep brain stimulation in Parkinson disease: a metaanalysis of patient outcomes," Journal of Neurosurgery, vol. 103, no. 6, pp. 956-967, 2005.

[46] M. R. Schoenberg, K. M. Mash, K. J. Bharucha, P. C. Francel, and J. G. Scott, "Deep brain stimulation parameters associated with neuropsychological changes in subthalamic nucleus stimulation for refractory Parkinson's disease," Stereotactic and Functional Neurosurgery, vol. 86, no. 6, pp. 337-344, 2008.

[47] R. J. Siegert, M. Weatherall, K. D. Taylor, and D. A. Abernethy, "A meta-analysis of performance on simple span and more complex working memory tasks in Parkinson's disease," Neuropsychology, vol. 22, no. 4, pp. 450-461, 2008.

[48] M. Broen, A. Duits, V. Visser-Vandewalle, Y. Temel, and A. Winogrodzka, "Impulse control and related disorders in Parkinson's disease patients treated with bilateral subthalamic nucleus stimulation: a review," Parkinsonism and Related Disorders, vol. 17, no. 6, pp. 413-417, 2011.

[49] T. Wu and M. Hallett, "The cerebellum in Parkinson's disease," Brain, vol. 136, no. 3, pp. 696-709, 2013.

[50] M. C. Keuken, L. Van Maanen, R. Bogacz et al., "The subthalamic nucleus during decision-making with multiple alternatives," Human Brain Mapping, vol. 36, no. 10, pp. 4041-4052, 2015.

[51] T. D. Parsons, S. A. Rogers, A. J. Braaten, S. P. Woods, and A. I. Tröster, "Cognitive sequelae of subthalamic nucleus deep brain stimulation in Parkinson's disease: a meta-analysis," The Lancet Neurology, vol. 5, no. 7, pp. 578-588, 2006.

[52] J. Sánchez-Meca, "Cómo realizar una revisión sistemática y un meta-análisis," Aula Abierta, vol. 38, pp. 53-63, 2010.

[53] A. Liberati, D. G. Altman, J. Tetzlaff et al., "The PRISMA statement for reporting systematic reviews and meta-analyses of studies that evaluate health care interventions: explanation and elaboration," PLoS Medicine, vol. 6, no. 7, Article ID e1000100, 2009.

[54] L. Castelli, M. Lanotte, M. Zibetti et al., "Apathy and verbal fluency in STN-stimulated PD patients: An Observational Follow-up Study," Journal of Neurology, vol. 254, no. 9, pp. 12381243, 2007.

[55] F. Le Jeune, J. Péron, I. Biseul et al., "Subthalamic nucleus stimulation affects orbitofrontal cortex in facial emotion recognition: A Pet Study," Brain, vol. 131, no. 6, pp. 1599-1608, 2008.

[56] K. Witt, C. Daniels, J. Reiff et al., "Neuropsychological and psychiatric changes after deep brain stimulation for Parkinson's disease: a randomised, multicentre study," The Lancet Neurology, vol. 7, no. 7, pp. 605-614, 2008.
[57] L. Yang, G.-D. Zhan, J.-J. Ding et al., "Psychiatric illness and intellectual disability in the prader-willi syndrome with different molecular defects-a meta analysis," PLOS ONE, vol. 8, no. 8, Article ID e72640, 2013.

[58] J. A. C. Sterne and M. Egger, "Funnel plots for detecting bias in meta-analysis: guidelines on choice of axis," Journal of Clinical Epidemiology, vol. 54, no. 10, pp. 1046-1055, 2001.

[59] M. Borenstein, L. V. Hedges, J. P. T. Higgins, and H. R. Rothstein, "A basic introduction to fixed- effect and random-effects models for meta-analysis," Research Synthesis Methods, vol. 1, no. 2, pp. 97-111, 2010.

[60] B. T. Johnson, L. A. J. Scott-Sheldon, L. B. Snyder, S. M. Noar, and T. B. Huedo-Medina, "Contemporary approaches to metaanalysis in communication research: SAGE research methods," in The SAGE Sourcebook of Advanced Data Analysis Methods for Communication Research, A. F. Hayes, M. D. Slater, and L. B. Snyder, Eds., SAGE, Los Angeles, Calif, USA, 2008.

[61] B. Wu, L. Han, B.-M. Sun, X.-W. Hu, and X.-P. Wang, "Influence of deep brain stimulation of the subthalamic nucleus on cognitive function in patients with Parkinson's disease," Neuroscience Bulletin, vol. 30, no. 1, pp. 153-161, 2014.

[62] H. M. Gray and L. Tickle-Degnen, "A meta-analysis of performance on emotion recognition tasks in Parkinson's disease," Neuropsychology, vol. 24, no. 2, pp. 176-191, 2010.

[63] M. K. York, E. A. Wilde, R. Simpson, and J. Jankovic, "Relationship between neuropsychological outcome and DBS surgical trajectory and electrode location," Journal of the Neurological Sciences, vol. 287, no. 1-2, pp. 159-171, 2009.

[64] A. Fasano, A. Daniele, and A. Albanese, "Treatment of motor and non-motor features of Parkinson's disease with deep brain stimulation," The Lancet Neurology, vol. 11, no. 5, pp. 429-442, 2012.

[65] M. L. Waterfall and S. F. Crowe, "Meta-analytic comparison of the components of visual cognition in Parkinson's disease," Journal of Clinical and Experimental Neuropsychology, vol. 17, no. 5, pp. 759-772, 1995.

[66] Y.-X. Sun, X.-H. Wang, A.-H. Xu, and J.-H. Zhao, "Functional polymorphisms of the MAO gene with Parkinson disease susceptibility: a meta-analysis," Journal of the Neurological Sciences, vol. 345, no. 1, pp. 97-105, 2014.

[67] F. Caire, D. Ranoux, D. Guehl, P. Burbaud, and E. Cuny, "A systematic review of studies on anatomical position of electrode contacts used for chronic subthalamic stimulation in Parkinson's disease," Acta Neurochirurgica, vol. 155, no. 9, pp. 1647-1654, 2013.

[68] R. Pavão, A. F. Helene, and G. F. Xavier, "Parkinson's disease progression: implicit acquisition, cognitive and motor impairments, and medication effects," Frontiers in Integrative Neuroscience, vol. 6, article 56, 2012. 


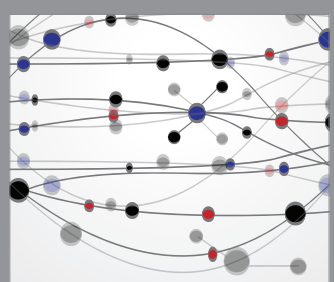

The Scientific World Journal
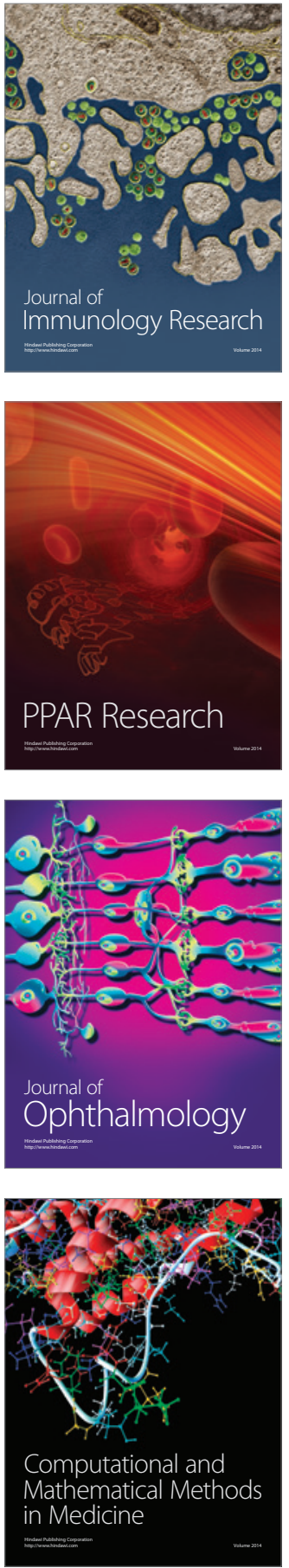

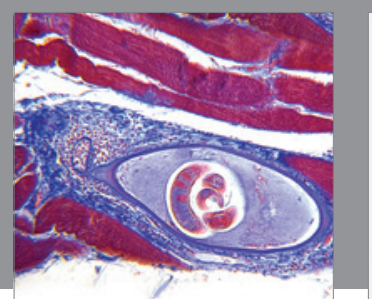

Gastroenterology Research and Practice
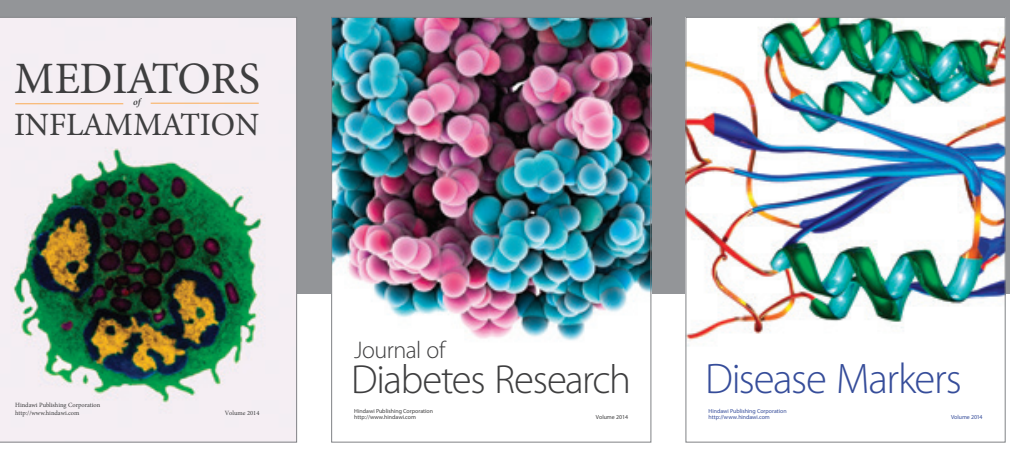

Disease Markers

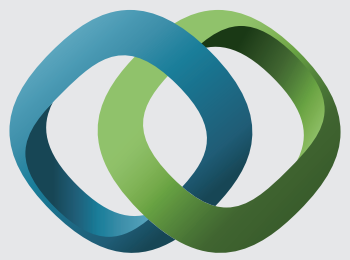

\section{Hindawi}

Submit your manuscripts at

https://www.hindawi.com
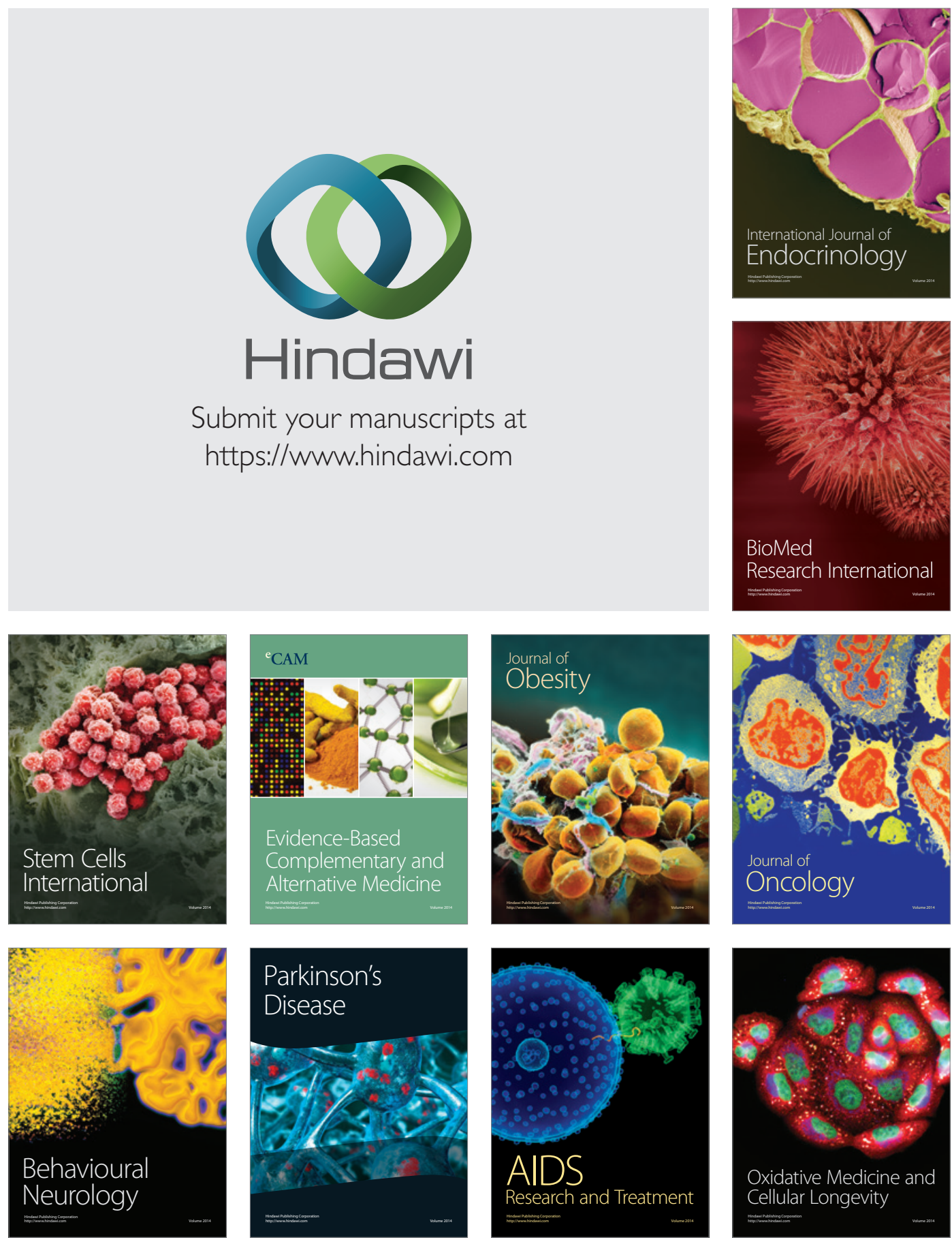